\title{
Effect of mechanically deboned poultry meat content on technological properties and sensory characteristics of lamb and mutton sausages
}

\author{
Armando Abel Massingue ${ }^{1,2}$, Robledo de Almeida Torres Filho ${ }^{3}$, Paulo Rogério Fontes ${ }^{1}$, \\ Alcinéia de Lemos Souza Ramos ${ }^{1}$, Edimar Aparecida Filomeno Fontes ${ }^{4}$, \\ Juan Ramon Olalquiaga Perez ${ }^{5}$, and Eduardo Mendes Ramos ${ }^{1, *}$
}

* Corresponding Author: Eduardo Mendes Ramos Tel: +55-35-3829-1403, Fax: +55-35-3829-1401,

E-mail: emramos@dca.ufla.br

'Departamento de Ciência dos Alimentos, Universidade Federal de Lavras, P.O. Box 3037, Lavras, MG 37200-000, Brazil

2 Escola Superior de Desenvolvimento Rural, Universidade Eduardo Mondlane, Inhambane, 1308 Mozambique

${ }^{3}$ Instituto de Ciências Exatas e Tecnológicas, Universidade Federal de Viçosa, Campus UFV Florestal, Florestal, MG 35690-000, Brazil

${ }^{4}$ Departamento de Tecnologia de Alimentos,

Universidade Federal de Viçosa, Viçosa, MG 36570 -

000, Brazil

${ }^{5}$ Departamento de Zootecnia, Universidade Federal de Lavras, P.O. Box 3037, Lavras, MG, 37200-000, Brazil

ORCID

Armando Abel Massingue

https://orcid.org/0000-0002-1967-2152

Robledo de Almeida Torres Filho

https://orcid.org/0000-0003-1760-0419

Paulo Rogério Fontes

https://orcid.org/0000-0003-2491-2891

Alcinéia de Lemos Souza Ramos

https://orcid.org/0000-0001-5510-5131

Edimar Aparecida Filomeno Fontes

https://orcid.org/0000-0002-4370-8805

Eduardo Mendes Ramos

https://orcid.org/0000-0002-8240-8151

Submitted Jun 21, 2017; Revised Aug 9, 2017; Accepted Sept 11, 2017
Objective: This study aimed to develop a value-added product concerning technological and sensory characteristics changes of the use of mechanically deboned poultry meat (MDPM) as meat replacer in lamb and mutton emulsion-type sausages (mortadella).

Methods: Sausages were produced with lamb and mutton and with different contents of MDPM. Six treatments, using lamb or mutton and $0 \%, 30 \%$, and $60 \%$ of MDPM in relation to the meat batter, were produced and analyzed for $\mathrm{pH}$, proximal composition, calcium and residual nitrite content, water activity, 2-thiobarbituric acid reactive substances (TBARS), instrumental color and texture profile. The sensory profile of the mortadella's was also evaluated by acceptance test and check-all-that-applies (CATA) analysis.

Results: The MDPM addition increased $(p<0.05)$ fat, residual nitrite and calcium content in the all sausage formulations, but mutton sausage had $(\mathrm{p}<0.05)$ higher fat and lower moisture content than lamb sausage. The $\mathrm{pH}$, water activity, TBARS index and color was not affected by MDPM additions, while the mutton sausages were significantly redder (higher $a^{\star}, C^{\star}$, and lower $h^{\circ}$ ) and darker (lower $L^{\star}$ ) than lamb sausages. Adding up to 60\% of MDPM reduced $(p<0.05)$ sausages hardness and chewiness. Overall, the meat replacement by MDPM increased the sausages acceptance, but the mutton sausage with 30\% of MDPM replacer were the most preferred. Consumers related that pink color, glossy appearance, poultry meat-like taste, soft texture, juicy and greasy mouth feel to all sausages contain MDPM according to CATA analysis. Conclusion: Mutton from culled ewes can be utilized for mortadella production with 30\% replacement of lean mutton and fat by MDPM.

Keywords: Mortadella; Sheep Meat; Discarded Animals; Check-all-that-applies Analysis

\section{INTRODUCTION}

Ovine are distributed all over the world, with an annual growth rate of $1.5 \%$ in the latest 5 years. In 2014, the world herd was about 1.2 billion domesticated animals, with a projection of slight growth in 2016 [1]. On a global scale, the estimative for sheep meat production in 2016 is relatively low, with less than 14.4 million tonnes, when compared to beef ( 68 million tonnes), pork (115 million tonnes), and poultry (117 million tonnes) [2].

In Brazil, irregular supply of sheep meat has been considered the main responsible for its low consumption [3]. Lamb has higher commercial value, mainly due to the young age of this category, with great acceptance by the consumer market [4]. Furthermore, the high fat content, low tenderness and the distinct flavor of mutton $[4,5]$ may result in the decline of its marketing value. 
Industrialization of culled sheep carcasses in processed meat products is a strategy to stimulate the consumption of the meat of older animals. Currently, there are some mutton products on the market such as sausages [5-8] and salami [9]. It has also been reported the good characteristics of the drycured ham [10] and ham-type pâté [4] prepared of mutton. There is still a lot of effort to develop more products considering the range of products offered using other meats (beef, pork, and poultry) containing different ingredients. Noticeably, the mechanically deboned poultry meat (MDPM) is one of the ingredients that has widely been used in mortadella.

Regardless the related products present themselves as alternative for the consumer market, studies indicating the use of goat or sheep meats mixed with MDPM to prepare their meat emulsions are scarce. The MDPM is reported as raw material with good nutritional and functional properties for use in cooked meat products and its production in poultry industries has become economically important [11]. Despite its composition (higher fat content) and characteristics (rapid oxidation, reddish color, and perishability) that could limit its use in meat products [12], several researches [12-14] have considered the MDPM as potential ingredient to be used in the preparation of emulsified meat products because of its paste form.

Due to low production cost, soft or mushy texture and unique taste of MDPM [12], its incorporation as sausage ingredient offers an alternative to recover product texture and to improve sensory acceptance of the emulsified mutton sausage. Thus, the present study aimed to evaluate the technological effect of the use of different percentages of MDPM as lamb and mutton replacer upon the physicochemical and sensory acceptance of mortadella.

\section{MATERIALS AND METHODS}

Sausage manufacturing
Sausages were prepared using meat from 12-months old (lamb) and 60-months old (mutton) Santa Inês ewes, provided by Department of Animal Science of Federal University of Lavras. The animals were slaughtered in a commercial slaughterhouse after a 16-h period of solid fasting and a hydric diet, being stunned by cerebral concussion and bled by cutting the jugular veins and carotid arteries. The warm carcasses were chilled for $24 \mathrm{~h}$ at $2^{\circ} \mathrm{C}$, and the legs and shoulders cuts were deboned, vacuum packaged, frozen and stored at $-20^{\circ} \mathrm{C}$ prior to processing. The pork backfat was provided by a local slaughterhouse. The frozen MDPM, with less than 30 days of storage $\left(-18^{\circ} \mathrm{C}\right)$ and with the Federal Inspection Service seal, was donated by Pif Paf Alimentos Ltd. (Visconde do Rio Branco, MG, Brazil) and the additives (polyphosphates, curing salt, antioxidant, and mortadella's seasoning) by New Max Industrial Ltd. (Americana, SP, Brazil). The salt (sodium chloride) and cassava starch are purchased in local market.

Emulsion-type sausages (mortadella) were produced in a pilot plant at Laboratory of Technology of Meat and Meat Products (LabCarnes) of the Food Science Department of Federal University of Lavras. Three batches of sausage formulations were prepared for each type of sheep meat (lamb or mutton), and to each it was added MDPM (Table 1) such that the formulations contained either $0 \%, 30 \%$, or $60 \%$ of MDPM in relation to the meat batter (meat and pork fat). Excess fat on lamb and mutton was trimmed. Lean meat and pork fat were ground separately through $9 \mathrm{~mm}$ plates by a grinder (Beccaro PB-22 model, São Paulo, SP, Brazil) and stored at $-18^{\circ} \mathrm{C}$ until later use. Frozen raw meat and ice cubes were transferred to the cutter (Jamar K-10 model, Tupã, SP, Brazil) and the mincing started at maximum knife cutter speed. Phosphate was rapidly added. After $30 \mathrm{~s}$, salt was added, and the mincing process was continued for an additional $30 \mathrm{~s}$, at which point the MDPM and other ingredients (mortadella seasoning, curing salt, antioxidant, and cassava starch) were added. The mincing was continued until the batter reached $7^{\circ} \mathrm{C}$. The

Table 1. Formulations (\%) of sheep mortadella's prepared with different levels ${ }^{1)}$ of mechanically deboned poultry meat

\begin{tabular}{|c|c|c|c|c|c|c|}
\hline \multirow{2}{*}{ Ingredients } & \multicolumn{3}{|c|}{ Lamb sausage } & \multicolumn{3}{|c|}{ Mutton sausage } \\
\hline & LO & L30 & $\mathrm{L} 60$ & M0 & M30 & M60 \\
\hline Sheep meat & 57 & 36 & 15 & 57 & 36 & 15 \\
\hline Pork fat & 14 & 14 & 14 & 14 & 14 & 14 \\
\hline MDPM & 0 & 21 & 42 & 0 & 21 & 42 \\
\hline Ice water & 20 & 20 & 20 & 20 & 20 & 20 \\
\hline Cassava starch & 5 & 5 & 5 & 5 & 5 & 5 \\
\hline Salt (sodium chloride) & 2 & 2 & 2 & 2 & 2 & 2 \\
\hline Polyphosphates & 0.5 & 0.5 & 0.5 & 0.5 & 0.5 & 0.5 \\
\hline Curing salt (sodium nitrite) & 0.3 & 0.3 & 0.3 & 0.3 & 0.3 & 0.3 \\
\hline Antioxidant (sodium erythorbate) & 0.25 & 0.25 & 0.25 & 0.25 & 0.25 & 0.25 \\
\hline Mortadella's seasoning & 0.5 & 0.5 & 0.5 & 0.5 & 0.5 & 0.5 \\
\hline
\end{tabular}

MDPM, mechanically deboned poultry meat.

1) $0 \%, 30 \%$, and $60 \%$ of MDPM in relation to the meat batter (meat+pork fat). L, lamb; M, mutton. 
pork backfat were then added, and the mincing was continued at low velocity until the emulsified batter reached $12^{\circ} \mathrm{C}$. The emulsify batter was stuffed into polyamide artificial casing (Spel Food Packaging, São Paulo, SP, Brazil) 67 diameter $\times 200 \mathrm{~mm}$ long size, using a manual stuffer (Picelli, EP-5 model, Rio Claro, SP, Brazil) to produce sausages with approximately 400 $\mathrm{g}$, clipped at both ends (MGE polyclip system MLE-300 model, São Paulo, SP, Brazil) and cooked in a water bath to an internal temperature of $72^{\circ} \mathrm{C}$ following a previously established cooking set-up: $55^{\circ} \mathrm{C}$ for $30 \mathrm{~min}, 65^{\circ} \mathrm{C}$ for $30 \mathrm{~min}, 75^{\circ} \mathrm{C}$ for $30 \mathrm{~min}$, and $85^{\circ} \mathrm{C}$ for $30 \mathrm{~min}$. When the endpoint temperature was achieved, the sausages were immediately chilled on ice and stored at $4^{\circ} \mathrm{C}$ until analysis.

\section{Chemical composition and physicochemical analysis}

The raw material (lamb, mutton, and MDPM) and sausages samples were subjected to physical and chemical analysis in triplicate, according to the official methods of the AOAC [15]. The proximate composition (\%) was estimated by measuring the total moisture (AOAC 950.46B), fat (AOAC 960.39), protein (AOAC 981.10, using 6.25 as conversion factor), and ash (AOAC 950.46) contents. Samples were also analyzed for calcium (\% on a dry matter basis; AOAC 975.03) and for residual sodium nitrite ( $\mathrm{mg} \mathrm{NaNO} / \mathrm{kg}$ of sample; AOAC 973.31).

The $\mathrm{pH}$ of the products was measured using a digital $\mathrm{pH}$ meter (Digimed model DM20, São Paulo, SP, Brazil) after homogenization of $5 \mathrm{~g}$ of sample in $50 \mathrm{~mL}$ of distilled water. For water activity (Aw), samples were ground and direct analyzed in an AquaLab CX2 (Decagon Devices, Inc., Pullman, WA, USA) hygrometer. The level of lipid oxidation in the products was assessed by measuring the 2-thiobarbituric acid reactive substances (TBARS) proposed by Raharjo et al [16], with modifications described by Jorge et al [17]. The concentration of malonaldehyde (MDA) was determined using an analytical curve of 1.1.3.3-tetraethoxypropane and the TBARS values were expressed as mg MDA/kg of sample.

\section{Color and texture instrumental analysis}

Sausages were tested by instrumental color, using a Minolta CM-700 (Konica Minolta, Tokyo, Japan) colorimeter, and by texture profile analysis (TPA), using a universal Texture Analyzer TA.XT2i (Stable Micro Systems Ltd., Godalming, UK), as describe by Ramos and Gomide [18].

The sausage color was measured by the CIELAB system with a D65 standard illuminant, an observer angle of $10^{\circ}$, aperture of $8 \mathrm{~mm}$ and specular component excluded mode. The sausages were sliced in half and six measurements representing the entire internal cross-section surface were taken from each sample. Lightness $\left(L^{*}\right)$, redness $\left(a^{*}\right)$ and yellowness $\left(b^{*}\right)$ were recorded. The angular coordinates of chroma $\left(C^{\star}\right)$ and hue angle $\left(h^{\circ}\right.$, graus) were calculated using the following formulas: $C^{\star}=\left(a^{\star^{2}}+b^{\star 2}\right)^{1 / 2}$ and $h^{\circ}=\tan ^{-1}\left(b^{\star} / a^{\star}\right)$. Higher $C^{\star}$ values suggests more vivid color; and $h^{\circ}$ values near 0 are red and near $90^{\circ}$ are yellow.

For the TPA test, six cubes (with $10 \mathrm{~mm}$ edge cores) were obtained from each sample and compressed twice to $50 \%$ of their original height, at room temperature, with compression flat cylindrical aluminum probe (36 mm diameter). A crosshead speed of $180 \mathrm{~mm} / \mathrm{min}$ was applied. There was no rest time between the two cycles of compression. Force time curves were recorded during compression and five texture attributes were calculated: i) hardness $(\mathrm{N})$, peak force required for first compression; ii) springiness ( $\mathrm{mm}$ ), distance sample recovers after first compression; iii) adhesiveness $(\mathrm{N} \mathrm{mm})$, the negative force area for the first bite representing the work necessary to pull the compressing plunger away from the sample; iv) cohesiveness, ratio of positive force area during the second compression to that in the first compression; and v) chewiness $(\mathrm{N} \mathrm{mm})$, the product of hardness, cohesiveness and springiness.

\section{Sensory evaluation}

Sensory analyses were performed at Sensorial Laboratory at Food Science Department of Federal University of Lavras after approval by the National Research Ethics System (SISNEP, Brazil) under protocol CAAE 0023.0.461.000-11.

To describe the sensory characteristics of each product, the check-all-that-apply (CATA) questions were used according to Jorge et al [17]. Firstly, the CATA questions were defined by 19 untrained participants, consisted of undergraduate and graduate students, with ages ranging from 18 to 30 years old, randomly recruited at UFLA. All participants were frequent consumers (more than twice per week) of mortadella. Cubes of approximately $25 \mathrm{~mm}$ edge of each sample were presented in a single testing session (Repertory Grid technique), and judges used an open-ended question to establish the appropriate terms for describing their appearance, flavor and texture. The most mentioned terms for each attribute were chosen to compose the CATA questions (Table 2).

In the second stage, 53 untrained participants, consisting of professors, undergraduate and graduate students, 20 males and 33 females, with ages ranging from 18 to 50 years old, were randomly recruited at UFLA. All participants declared to be mortadella consumers. The sensory analysis was performed

Table 2. Terms surveyed for check-all-that-apply (CATA) questions of each sensory attribute

\begin{tabular}{lll}
\hline Appearance & Flavor & Texture \\
\hline Red color & Poultry meat-like taste & Firm texture \\
Pink color & Ovine meat-like taste & Soft texture \\
Light color & Bitter aftertaste & Rubbery texture \\
Dark color & & Juiciness \\
Glossiness & & Greasiness \\
\hline
\end{tabular}


in a single testing session conducted in individual cabins with white light. Sample cubes of approximately $20 \mathrm{~mm}$ edge were labeled with a 3-digit code and were offered to the panelist randomly and balanced in a monadic sequence. Mineral water was offered to the panelists for mouth rinsing between sample trials. The panelists received the sensory evaluation form (acceptance test) and evaluated the samples using a hedonic scale of 1 (disliked very much) to 9 (liked very much) for each attribute (flavor, texture and overall impression). In the same form, the panelists were asked to check all the terms of CATA questions (as previously defined, Table 2) considered appropriate to describe each attribute.

\section{Statistical analysis}

The experiment was conducted in a completely randomized design in a 2 (lamb and mutton) $\times 3(0 \%, 30 \%$, and $60 \%$ MDPM) factorial arrangement with three repetitions (batches). The resulting data was tested by F-test (analysis of variance) and, when was significant $(\mathrm{p}<0.05)$, the means were separated using Tukey's test.

For the acceptance test, each attribute was analyzed individually with an internal preference map (IPM), and the attributes of appearance, flavor and texture were simultaneously analyzed by a three-way internal preference map (IPM tri-plot), which is also known as parallel factor analysis (PARAFAC), according to Nunes et al [19].

To identify the relation between the CATA terms selected for each sample, an external preference map (EPM) was used. In EPM the analysis was based in the regression of external descriptors against consumer data (overall impression in this case) for each consumer. According to Elmore et al [20], models with less than $30 \%$ of significance could be considered valid to generate the EPM graphic, so only the slopes for consum- ers that provided valid models $(\mathrm{p} \leq 0.30)$ were plotted on the map.

Statistical analyses were performed using the SAS statistical (SAS Institute Inc., Cary, NC, USA) package, version 9.2. The IPM and EPM analyses were performed in the SensoMaker statistical software (Lavras, MG, Brazil), version 1.5.

\section{RESULTS AND DISCUSSION}

\section{Physicochemical characteristics}

The proximate composition and the physicochemical characteristics of sausages are shown in Table 3. No significant interaction was observed between the type of meat (lamb or mutton) and the levels of meat replacement by MDPM for any sausage characteristic. However, the samples from lamb had $(\mathrm{p}<0.05)$ higher moisture and lower fat contents than mutton sausages. This was due to the higher moisture $(74.02 \% \pm 0.76 \%)$ and lower fat $(6.13 \% \pm 0.50 \%)$ content observed $(\mathrm{p}<0.05)$ in lamb than in mutton $(72.26 \% \pm 0.96 \%$ of moisture and $8.42 \%$ $\pm 0.86 \%$ of fat). A similar behavior was observed with increasing amount of MDPM, which had $(\mathrm{p}<0.05)$ higher contents of fat $(17.61 \%$ vs $7.28 \%)$ and lower content in protein $(13.23 \%$ vs $17.97 \%)$ and water ( $67.57 \%$ vs $73.14 \%)$ than sheep meats, causing the observed changes of these constituents in the sausages. Guerra et al [5] also observed a decrease in the moisture and protein levels in goat mortadella due to increased lipid percentages.

Although all elaborated samples were within the limits established by the Brazilian legislation [21] for moisture (maximum of 65\%) and fat (maximum of 30\%) content, the minimum amount of $12 \%$ of protein was not achieved in the mortadella's with MDPM added. However, sausages may also be added of non-meat proteins, such as caseinates, whey and

Table 3. Proximate composition and physicochemical characteristics (mean values \pm standard deviations) of sheep mortadella's prepared with different levels ${ }^{1)}$ of mechanically deboned poultry meat

\begin{tabular}{|c|c|c|c|c|c|c|c|c|}
\hline \multirow{2}{*}{ Characteristics } & \multicolumn{2}{|c|}{ Meat type } & \multicolumn{3}{|c|}{ MDPM (\%) } & \multicolumn{3}{|c|}{$\operatorname{Pr}>F^{2 l}$} \\
\hline & Lamb & Mutton & 0 & 30 & 60 & $S$ & $M$ & $\mathrm{~S} \times \mathrm{M}$ \\
\hline \multicolumn{9}{|l|}{ Proximal composition } \\
\hline Moisture (\%) & $64.87 \pm 1.54^{\mathrm{a}}$ & $63.02 \pm 0.92^{b}$ & $65.07 \pm 1.66^{\mathrm{a}}$ & $63.82 \pm 1.50^{\mathrm{ab}}$ & $62.93 \pm 0.65^{b}$ & $<0.001$ & 0.003 & 0.143 \\
\hline Protein (\%) & $11.64 \pm 0.95$ & $11.42 \pm 1.31$ & $12.85 \pm 0.25^{\mathrm{a}}$ & $11.28 \pm 0.65^{b}$ & $10.46 \pm 0.49^{c}$ & 0.368 & $<0.001$ & 0.327 \\
\hline Fat $(\%)$ & $15.08 \pm 2.06^{b}$ & $17.16 \pm 2.20^{\mathrm{a}}$ & $13.88 \pm 2.00^{b}$ & $16.68 \pm 1.80^{\mathrm{a}}$ & $17.79 \pm 1.19^{\mathrm{a}}$ & 0.008 & 0.001 & 0.846 \\
\hline Ash (\%) & $3.47 \pm 0.58$ & $3.61 \pm 0.28$ & $3.56 \pm 0.16$ & $3.27 \pm 0.69$ & $3.77 \pm 0.13$ & 0.628 & 0.218 & 0.637 \\
\hline \multicolumn{9}{|l|}{ Physicochemical } \\
\hline Calcium (\% DMB) & $0.16 \pm 0.11$ & $0.15 \pm 0.10$ & $0.04 \pm 0.01^{c}$ & $0.15 \pm 0.02^{b}$ & $0.28 \pm 0.03^{\mathrm{a}}$ & 0.733 & $<0.001$ & 0.663 \\
\hline $\mathrm{pH}$ & $6.46 \pm 0.25$ & $6.32 \pm 0.15$ & $6.35 \pm 0.22$ & $6.39 \pm 0.28$ & $6.43 \pm 0.17$ & 0.227 & 0.832 & 0.801 \\
\hline Water activity & $0.968 \pm 0.004$ & $0.964 \pm 0.004$ & $0.967 \pm 0.004$ & $0.965 \pm 0.005$ & $0.965 \pm 0.005$ & 0.091 & 0.626 & 0.953 \\
\hline Residual nitrite (mg/kg) & $55.60 \pm 20.22$ & $57.66 \pm 25.69$ & $34.38 \pm 10.71^{b}$ & $56.95 \pm 11.52^{a b}$ & $78.56 \pm 17.09^{\mathrm{a}}$ & 0.773 & $<0.001$ & 0.874 \\
\hline TBARS value (mg MDA/kg) & $0.62 \pm 0.30$ & $0.63 \pm 0.27$ & $0.46 \pm 0.23$ & $0.74 \pm 0.34$ & $0.68 \pm 0.21$ & 0.974 & 0.279 & 0.883 \\
\hline
\end{tabular}

MDPM, mechanically deboned poultry meat; DMB, dry matter basis; TBARS, thiobarbituric acid reactive substances; MDA, malonaldehyde.

1) In relation to the meat batter (meat+pork fat).

2) Factors: S, sheep meat; M, MDPM. Significant probabilities $(p<0.05)$ were placed in bold.

${ }^{a-b}$ Means in the same row, into each effect, followed by different letters differ $(p<0.05)$. 
soy proteins, to a maximum of $4 \%$ as prescribed by the legislation, which may contribute to increase the protein content.

Regarding to the calcium content, all samples were in accordance with Brazilian legislation [21], which allows 0.6\% and $0.9 \%$ on a dry basis as maximum limits for mortadella's with $40 \%$ and $60 \%$ of MDPM added, respectively. Moreover, the calcium content in the sheep meat $(0.03 \%)$ was much lower than in MDPM (1.16\%), which explains the observed increase $(\mathrm{p}<0.05)$ of this mineral in mortadella's formulated with higher levels of MDPM. The amount of calcium in meat products has been used to monitoring the mechanically deboned meat addition [17].

The water activity $(\mathrm{Aw}=0.97 \pm 0.01), \mathrm{pH}(6.43 \pm 0.16)$, and TBARS values $(0.63 \pm 0.28 \mathrm{mg} \mathrm{MDA} / \mathrm{kg})$ of the mortadella were not ( $p>0.05$ ) affected by any of the evaluated factors (meat type and MDPM levels), being similar to those ( $\mathrm{Aw}=0.97$; $\mathrm{pH}=6.29$; and TBARS $=0.50 \mathrm{mg} \mathrm{MDA} / \mathrm{kg}$ ) observed by Dutra et al [4] in cooked ham-type pâté elaborated with mutton. Only residual nitrite levels were gradually increased $(\mathrm{p}<0.05)$ when meat was replaced by MDPM, not being affected by the type of sheep meat. The nitrite added is partly transformed to other nitrogen-containing compounds and bound to myoglobin and other meat constituents, as sulfhydryl compounds $[22,23]$. Therefore, the higher residual nitrite levels in the products added with MDPM may be explained based on the higher abundance of heme pigment expected in sheep meat, specially mutton, than in poultry, even mechanically deboned, inducing higher nitrosylheme formation and lower levels of residual nitrite. Shahidi and Pegg [24] reported twice as many heme pigment content in lamb $(2.1 \mathrm{mg} / \mathrm{g})$ than in mechanically deboned chicken meat $(1.0 \mathrm{mg} / \mathrm{g})$.

\section{Color and texture characteristics}

Table 4 shows the color and texture characteristics of sheep sausages prepared with different levels of MDPM. No significant interaction was observed between the type of sheep meat and MDPM levels for both characteristics.

The substitution of sheep meat with MDPM did not significantly affect the Commission Internationale de l'Eclairage (CIE) color indexes of the products (Table 4). This finding was not consistent with reports from others $[5,12,25]$ who stated that sausages become darker (lower $L^{*}$ values) when the fat content is reduced. According to Pietrasik [25], besides the fat content, the color of frankfurter-type products is also influenced by the added water and heme pigment content of the meat which they are made. Pereira et al [12] reported that redness $\left(a^{*}\right)$ and chroma $\left(c^{\star}\right)$ values increased with the high content of heme pigments in the sausage formulation. However, as previously described, the fat content of the final product was increased (Table 3) as the MDPM was added to the sausage formulation.

Nevertheless, the differences in the heme pigment content between the lamb and mutton can explain the differences observed $(\mathrm{p}<0.05)$ in the sausages colors made with them (Table 4). The increased weight and age at slaughter tend to increase the amount of pigments and red color and to reduce luminosity $\left(L^{\star}\right)$ of meats [26]. Thus, sausages made from mutton were darker (lower $L^{\star}$ values) and more reddish (lower $h^{\circ}$ values), with more intense color (higher $c^{\star}$ values). Shahidi and Pegg [23] reported that the increase in myoglobin content in cured products causes a decrease in $L^{\star}$ and $h^{\circ}$ values and a corresponding increase in $c^{\star}$ values.

For the texture parameters, replacements above $30 \%$ of sheep meat by MDPM in the sausages formulations reduced

Table 4. Instrumental color and texture characteristics (mean values \pm standard deviations) of sheep mortadella's prepared with different levels ${ }^{1)}$ of mechanically deboned poultry meat

\begin{tabular}{|c|c|c|c|c|c|c|c|c|}
\hline \multirow{2}{*}{ Characteristics } & \multicolumn{2}{|c|}{ Meat type } & \multicolumn{3}{|c|}{ MDPM (\%) } & \multicolumn{3}{|c|}{$\operatorname{Pr}>F^{2)}$} \\
\hline & Lamb & Mutton & 0 & 30 & 60 & $\mathbf{S}$ & M & $\mathrm{S} \times \mathrm{M}$ \\
\hline \multicolumn{9}{|l|}{ CIE color } \\
\hline Lightness $\left(L^{*}\right)$ & $59.66 \pm 1.63^{\mathrm{a}}$ & $56.99 \pm 2.38^{b}$ & $58.33 \pm 3.62$ & $58.62 \pm 2.05$ & $58.03 \pm 1.47$ & 0.032 & 0.911 & 0.945 \\
\hline Redness $\left(a^{*}\right)$ & $10.75 \pm 1.36^{b}$ & $13.32 \pm 2.66^{\mathrm{a}}$ & $11.96 \pm 2.48$ & $12.62 \pm 3.54$ & $11.53 \pm 0.89$ & 0.027 & 0.685 & 0.329 \\
\hline Yellowness $\left(b^{*}\right)$ & $11.90 \pm 0.93$ & $12.46 \pm 0.85$ & $11.69 \pm 1.04$ & $12.51 \pm 0.96$ & $12.34 \pm 0.62$ & 0.221 & 0.313 & 0.852 \\
\hline Chroma $\left(C^{*}\right)$ & $16.05 \pm 1.43^{b}$ & $18.29 \pm 2.40^{\mathrm{a}}$ & $16.76 \pm 2.46$ & $17.87 \pm 3.02$ & $16.88 \pm 0.97$ & 0.038 & 0.599 & 0.406 \\
\hline Hue angle $\left(h^{\circ}\right)$ & $48.00 \pm 2.74^{\mathrm{a}}$ & $43.52 \pm 4.17^{b}$ & $44.81 \pm 3.74$ & $45.51 \pm 6.19$ & $46.97 \pm 1.68$ & 0.021 & 0.576 & 0.317 \\
\hline \multicolumn{9}{|c|}{ Texture profile analysis (TPA) } \\
\hline Hardness (N) & $16.10 \pm 2.75$ & $15.59 \pm 2.92$ & $18.00 \pm 1.77^{\mathrm{a}}$ & $16.91 \pm 1.82^{\mathrm{a}}$ & $12.62 \pm 0.34^{b}$ & 0.517 & $<0.001$ & 0.948 \\
\hline Cohesiveness & $0.73 \pm 0.01^{\mathrm{a}}$ & $0.69 \pm 0.03^{b}$ & $0.71 \pm 0.02$ & $0.70 \pm 0.04$ & $0.72 \pm 0.01$ & 0.004 & 0.149 & 0.247 \\
\hline Adhesiveness $(\mathrm{N} \times \mathrm{mm})$ & $15.51 \pm 4.71$ & $13.15 \pm 3.87$ & $12.28 \pm 3.47$ & $16.91 \pm 4.72$ & $13.82 \pm 4.10$ & 0.271 & 0.211 & 0.879 \\
\hline Springiness (mm) & $5.01 \pm 0.49$ & $5.12 \pm 0.33$ & $4.87 \pm 0.33$ & $5.31 \pm 0.14$ & $5.01 \pm 0.58$ & 0.592 & 0.228 & 0.889 \\
\hline Chewiness $(\mathrm{N} \times \mathrm{mm})$ & $58.47 \pm 11.04$ & $55.30 \pm 10.61$ & $62.46 \pm 7.66^{\mathrm{a}}$ & $62.73 \pm 8.08^{a}$ & $45.45 \pm 5.01^{b}$ & 0.388 & 0.002 & 0.818 \\
\hline
\end{tabular}

CIE, Commission Internationale de I'Eclairage; MDPM, mechanically deboned poultry meat.

${ }^{1)}$ Regarding to the meat batter (meat+pork fat).

2) Factors: S, sheep meat; M, MDPM. Significant probabilities $(p<0.05)$ were placed in bold.

${ }^{a-b}$ Means in the same row, into each effect, followed by different letters differ $(p<0.05)$. 
$(p<0.05)$ the hardness and chewiness of the products without affecting other attributes (Table 4). The hardness reduction with the addition of MDPM in pork sausage was observed by Pereira et al [12]. Similar results were found by Daros et al [27], who observed that the use of MDPM to $60 \%$ in the preparation of sausage caused significant loss of compressive strength, and moderate addition of MDPM results in higher production strain and modulus of elasticity. Other authors [28] reported that $5 \%$ to $10 \%$ of flesh protein per MDPM caused a decrease in performance and flexibility, and the addition of MDPM in the mix seems to result in lower uniformity in the texture. The sausage prepared with the lamb showed greater cohesiveness $(\mathrm{p}<0.05)$ than that elaborated with mutton. This result may be due to the difference in fat content among the meat types (lamb had 12\% less fat than mutton). According to Pietrasik [25], cohesiveness tends to decrease as fat content increases. However, in the present study it was not observed any variation in cohesiveness parameter with MDPM addition in the sausages which promoted an increase in fat content and decrease of protein content as reported by Pereira et al [12]. On the other hand, Colmenero et al [29] also reported non-effect of fat content on cohesiveness of the sausages prepared with different fat content.

\section{Sensory analysis}

The majority of the judges were female (62.26\%). In addition, $69.81 \%$ of the judges were between 18 and 30 years old, 20.75\% were between 31 and 45 years old and 9.44\% were between 46 and 50 years old. Moreover, $66.0 \%$ of the judges reported that they consumed mortadella once per week, $4.8 \%$ twice a week, $23.0 \%$ twice a month, 5.0\% approximately once a month and $1.2 \%$ did not refer their frequency of mortadella consumption. None judges referred that they consumed mortadella daily.

Acceptance test: All the samples had typical sensory characteristics of mortadella's based on the Identity and Quality Standards established by the Brazilian legislation [21]. Overall, the scores attributed to the sausages were between 6 ("slightly liked") and 7 ("moderately liked"), which indicates a good acceptance of the product.

The sausage acceptance data were used to create an IPM for appearance, flavor and texture attributes and a PARAFAC plot (Figure 1), where the correlations between the samples, consumers and sensory attributes are shown simultaneously. For all parameters, the first two principal components (PCs) of the IPM explained approximately $55 \%$ of the variance in the data. In addition, the Core Consistency Diagnostic (CORCONDIA) of the PARAFAC model explained $75.89 \%$ of the correlation between these two factors. Nunes et al [30] reported that at least $45 \%$ of variance in the data and a $64 \%$ of CORCONDIA indicated that the model was adequate.

The PARAFAC plot resulted in spatial separation, which formed four distinct groups of samples. The two PC1 and PC2 clearly showed that samples M30 and L60 were the most preferred by consumers for all of the attributes, followed by samples M60 and L30. Samples without MDPM (L0 and M0) were less preferred and placed into two separate groups. These results indicate that increasing MDPM levels generally improved the sensory properties of sausages elaborated with sheep meat. Pereira et al [14] also observed that higher additions of MDPM in emulsified sausages implied higher acceptance scores by consumers. This is probably due to the fact that Brazilian consumers frequently eat processed meat products with a high amount of this ingredient, since Brazilian legislation allows the addition up to $60 \%$ of MDPM in emulsified products [21]. However, it is interesting to note that for mutton sausages the improvement in sensorial attributes was greater with the addition of $30 \%$ of MDPM. Also, by PARAFAC, it is observed that consumers preferred sausages made with mutton than those made with lamb.

Perhaps no characteristic of meat and meat products, with the possible exception of texture, is so important to consumer acceptance as is flavor. There is a consensus that as animal age increases so does the intensity of flavor and this may be due to higher concentrations of muscle lipid [31]. Butler-Hogg and Francombe [32] found that meat from lamb at the age of 16 weeks was less flavorsome than meat from lambs (hogget) at 43 weeks of age. Thus, the greater acceptance of mutton sausages can be due to the greater amount of fat present in the meat and a greater deposition of aromatic compounds throughout the animal's life.

For the acceptance test by IPM, the spatial separation of the overall impression attribute resulted in group of samples different from those observed in PARAFAC plot: samples with 30\% replacement of meat by MDPM (L30 and M30) were the most preferred, followed by samples M0 and L60 grouped together, by M60 sample and at last preferred L0. The samples grouped by this form was not observed in other sensorial attributes. This is due to the fact that each consumer weighted the appearance, flavor and texture attributes differently when determining his or her overall impression. However, despite the grouping differences, it is observed that for all attributes the mutton sausage containing 30\% of MDPM (M30) was the most preferred and the lamb sausage the least preferred (L0). Also, in general, the lower preference for the non-added MDPM samples observed in PARAFAC appears to be especially due to texture and, to a lesser extent, to flavor.

Check-all-that-apply (CATA): The EPM was generated from the number of times that the consumers associated each of the 13 sensory terms of the CATA questions (Table 2) with the samples and overall impression scores from acceptance test. According to Elmore et al [20], models with less than 30\% of significance could be considered valid to generate the EPM graphic. Therefore, only the slopes for 24 consumers (of the 


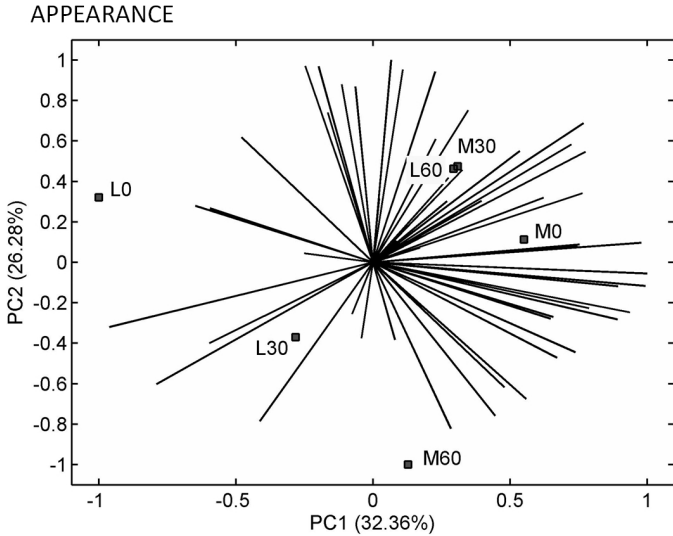

TEXTURE

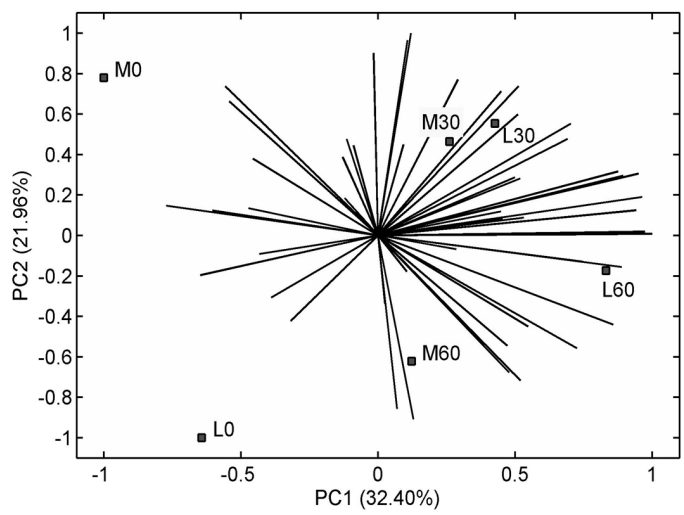

FLAVOR

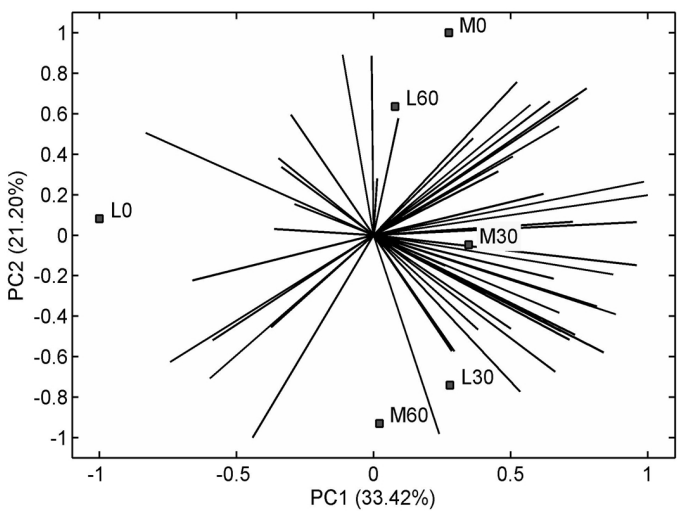

OVERAL IMPRESSION

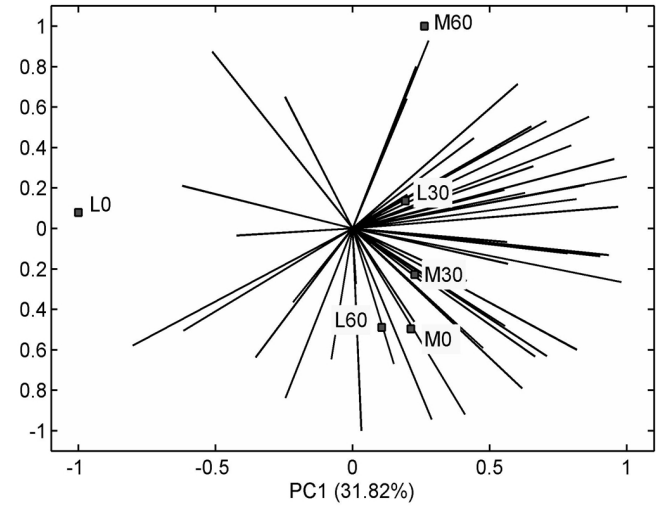

PARAFAC

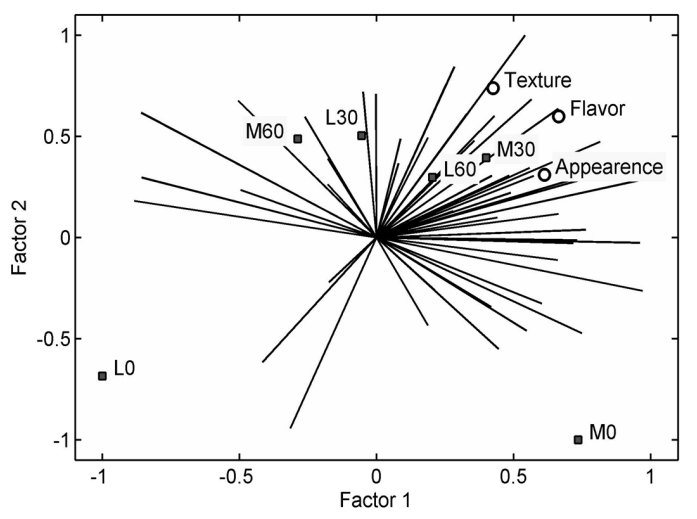

Figure 1. Internal preference maps (IPM) for the appearance, flavor, texture and overall impression of the sheep mortadella samples. The internal preference map for the Tri-plot (PARAFAC) of appearance, flavor and texture of the mortadella based on their consumer scores (shown as vectors in the plot) in the acceptance test is also shown. L, lamb sausage; $\mathrm{M}$, mutton sausage; and $0,30,60$, percentage of mechanically deboned poultry meat (MDPM) in relation to the meat batter (meat+pork fat).

53 participants) that provided valid models $(\mathrm{p}<0.25)$ were plotted on the map upon two PCs (Figure 2).

The PC plots show the relative positions of the samples and factor loadings indicate the attributes that best describe the dimensions of the perceptive space. Combined, the PC1 and PC2 accounted for $81.72 \%$ of the total variance in the data after fitting by the vector model with a coefficient of determination $\left(\mathrm{R}^{2}\right)$ of 0.7655 .

First, the spatial separation of the samples with MDPM added (L30, L60, M30, and M60) could be grouped together against sausages with only sheep meat ( $\mathrm{L} 0$ and $\mathrm{M} 0$ ). The samples with added MDPM were distinguished in the first PC by the perceived poultry meat taste, by its greasy, juicy and soft texture, and by its pink color, glossy and uniform appearance. Unfortunately, the bitter aftertaste, the red/dark color and the firm, rubbery and porous texture (very rigid protein matrix) were perceived in the sheep sausages. Moreover, the dispersion of consumer acceptance vectors indicates that the formula- 


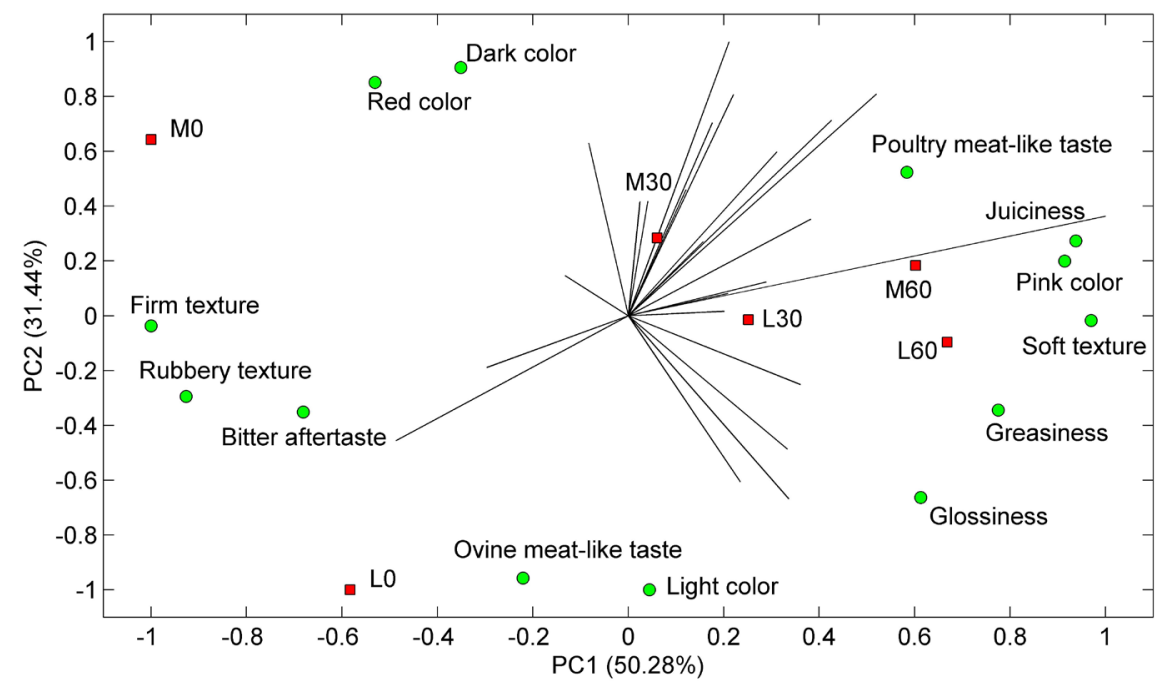

Figure 2. External preference map (EPM) of the sensory terms on the check-all-that-apply (CATA) questionnaire for the sheep mortadella samples in the correlation matrix with overall consumer impression. L, lamb sausage; $M$, mutton sausage; and $0,30,60$, percentage of mechanically deboned poultry meat (MDPM) in relation to the meat batter (meat+pork fat).

tions containing MDPM were most accepted than the sheep sausages, corroborating what was observed in the acceptance data by the IPM and PRAFAC plots.

By the EPM spatial separation it is also possible to form five distinct groups of samples, which had different acceptances according to the graphic vectors. Samples L60 and M60 were grouped together and the others samples individually placed into four separate groups. The M30 sample was more accepted by consumers, and was different from the other sausages added by MDPM due to a lower association with the perception of the sample with rancid and poultry meat taste, soft texture and darker/reddish color.

\section{CONCLUSION}

The results showed that a high-quality value-added sheep product can be produced using lamb or mutton and with MDPM added, since all the formulations were sensorially well accepted. The results also indicate that the increase in meat substitution by MDPM improved the sensory properties of the sheep sausages, with little modification in the physicochemical and technological characteristics of the products. Moreover, consumers preferred mortadellas made from mutton than those made with lamb. Therefore, the use of mutton meat in the preparation of mortadella allows getting the most from this low-cost raw material, and the addition of $30 \%$ of MDPM resulted in a processed meat product with better acceptance and similar properties as those of lamb.

\section{CONFLICT OF INTEREST}

We certify that there is no conflict of interest with any financial organization regarding the material discussed in the manuscript.

\section{ACKNOWLEDGMENTS}

The authors would like to thank the Fundação de Amparo à Pesquisa do Estado de Minas Gerais (FAPEMIG; CVZ APQ02015-15) and the Conselho Nacional de Desenvolvimento Científico e Tecnológico (CNPq; MCT 430206/2016-0) for their financial support and both to the Coordenação de Aperfeiçoamento de Pessoal de Nível Superior (CAPES; Programa de Estudantes, Convénio de Pós-Graduação - PEC-PG) and Government of Mozambique for granting the scholarship (doctoral degree) to the first author and the CAPES for the scholarship granted (post-doctoral PNPD/CAPES) to the third author.

\section{REFERENCES}

1. FAO, FAOSTAT Database [internet]. Food and Agriculture Organization of the United Nations [cited 2017 may 5]. Available from: http://www.fao.org/faostat/en/\#home

2. FAO. Food Outlook Report: June 2017. Rome, Italy: Food and Agriculture Organization of the United Nations; 2017.

3. Olalgaquiaga Perez JR, Bressan MC, Bragagnolo N, et al. Effect of different lamb breed and their slaughter weights on cholesterol, fatty acid profile and proximate composition. Food Sci Technol (Campinas) 2002;22:11-8.

4. Dutra MP, Palhares PC, Silva JRO, et al. Technological and quality characteristics of cooked ham-type pâté elaborated with sheep meat. Small Rumin Res 2013;115:56-61.

5. Guerra ICD, Félex SSS, Meireles BRLM, et al. Evaluation of 
goat mortadella prepared with different levels of fat and goat meat from discarded animals. Small Rumin Res 2011;98:59-63.

6. Guerra ICD, Meireles BRLA, Félex SSS, et al. Spent lamb meat in the preparation of mortadella with different levels of pork fat. Cienc Rural 2012;42:2288-94.

7. Abdullah BM. Beef and sheep mortadella: formulation, processing and quality aspects. Int J Food Sci Technol 2004;39: 177-182.

8. Leite A, Rodrigues S, Pereira E, et al. Physicochemical properties, fatty acid profile and sensory characteristics of sheep and goat meat sausages manufactured with different pork fat levels. Meat Sci 2015;105:114-20.

9. François P, Pires CC, Griebler L, et al. Physico-chemical and sensorial properties of fermented sausages formulated with different proportions of meat from swine and culling ewes. Cienc Rural 2009;39:2584-9.

10. Stojković S, Grabež V, Bjelanović M, et al. Production process and quality of two different dry-cured sheep hams from Western Balkan countries. LWT Food Sci Technol 2015;64: 1217-24.

11. Jayathilakan K, Sultana K, Radhakrishna K, Bawa AS. Utilization of byproducts and waste materials from meat, poultry and fish processing industries: a review. J Food Sci Technol 2012;49: 278-93.

12. Pereira AGT, Ramos EM, Teixeira JT, et al. Effects of the addition of mechanically deboned poultry meat and collagen fibers on quality characteristics of frankfurter-type sausages. Meat Sci 2011;89:519-25.

13. Mielnik MB, Aaby K, Rolfsen K, Ellenkjaer MR, Nilsson A. Quality of comminuted sausages formulated from mechanically deboned poultry meat. Meat Sci 2002;61:73-84.

14. Pereira AGT, Cardoso GP, Teixeira JT, et al. Composition, collagen content and sensory quality of sausages elaborated with mechanically separated meat poultry and collagen fiber. Braz J Food Res (REBRAPA) 2016;7:131-48.

15.AOAC. Official methods of analysis of AOAC International. Gaithersburg, MD: Association of Official Analytical Chemists; 2012.

16. Raharjo S, Sofos JN, Schmidt GR. Improved speed, specificity, and limit of determination of an aqueous acid extraction thiobarbituric acid-C18 method for measuring lipid peroxidation in beef. J Agric Food Chem 1992;40:2182-5.

17. Jorge EC, Mendes ACG, Auriema BE, et al. Application of a check-all-that-apply question for evaluating and characterizing meat products. Meat Sci 2015;100:124-33.

18. Ramos EM, Gomide LAM. Meat quality analysis: fundamentals and methodologies. Viçosa, Brazil: Editora UFV; 2017.
19. Nunes CA, Pinheiro ACM, Bastos SC. Evaluating consumer acceptance tests by three-way internal preference mapping obtained by parallel factor analysis (PARAFAC). J Sens Stud 2011;26:167-74.

20.Elmore JR, Heymann H, Johnson J, Hewett JE. Preference mapping: relating acceptance of "creaminess" to a descriptive sensory map of a semi-solid. Food Qual Prefer 1999;10:465-75.

21. Brazil. Ministry of Agriculture, Livestock and Food Supply (MAPA), Secretaria for the Defence of Agribusiness (SDA). Normative Instruction no. 04, March 31, 2000. Technical regution of identity and quality of mechanically separated meat and sausages. Off J Federative Repub Brazil 2000;1:6-10.

22. Honikel KO. The use and control of nitrate and nitrite for the processing of meat products. Meat Sci 2008;78:68-76.

23. Shahidi F, Pegg RB. Nitrite alternatives for processed meats. In: George C, editors. Food Flavors: Generation, Analysis and Process Influence, Proceedings of the 8th International Flavor Conference. Cos, Greece: Elsevier; 1995. p. 1223-41.

24. Shahidi F, Pegg RB. Effect of the preformed cooked curedmeat pigment (CCMP) on color parameters of muscle foods. J Muscle Foods 1991;2:297-304.

25. Pietrasik Z. Effect of content of protein, fat and modified starch on binding textural characteristics, and colour of comminuted scalded sausages. Meat Sci 1999;51:17-25.

26. Juárez M, Horcada A, Alcalde MJ, et al. Meat and fat quality of unweaned lambs as affected by slaughter weight and breed. Meat Sci 2009;83:308-13.

27.Daros FG, Masson ML, Amico SC. The influence of the addition of mechanically deboned poultry meat on the rheological properties of sausage. J Food Eng 2005;68:185-9.

28. Thomsen $\mathrm{HH}$, Zeuthen P. The influence of mechanically deboned meat and $\mathrm{pH}$ on the water-holding capacity and texture of emulsion type meat products. Meat Sci 1988;22:189-201.

29. Colmenero FJ, Barreto G, Mota N, Carballo J. Influence of protein and fat content and cooking temperature on texture and sensory evaluation of bologna sausage. LWT Food Sci Technol 1995;28:481-7.

30. Nunes CA, Bastos SC, Pinheiro ACM, Pimenta CJ, Pimenta MESG. Relating consumer acceptance to descriptive attributes by three-way external preference mapping obtained by parallel factor analysis (PARAFAC). J Sens Stud 2012;27:209-16.

31. Young OA, Berdagué JL, Viallon C, Rousset-Akrim S, Theriez M. Fat-borne volatiles and sheepmeat odour. Meat Sci 1997; 45:183-200.

32. Butler-Hogg BW, Francombe MA. Carcass and meat quality in spring and hogget lamb. P Brit Soc Anim Prod 1985;40:527. 